\title{
Effects of Process-Oriented Worked Examples on Troubleshooting Transfer Performance
}

Citation for published version (APA):

Van Gog, T., Paas, G. W. C., \& van Merrienboer, J. J. G. (2006). Effects of Process-Oriented Worked Examples on Troubleshooting Transfer Performance. Learning and Instruction, 16(2), 154-164.

https://doi.org/10.1016/j.learninstruc.2006.02.003

DOI:

10.1016/j.learninstruc.2006.02.003

Document status and date:

Published: 01/04/2006

Document Version:

Peer reviewed version

Please check the document version of this publication:

- A submitted manuscript is the version of the article upon submission and before peer-review. There can be important differences between the submitted version and the official published version of record. People interested in the research are advised to contact the author for the final version of the publication, or visit the DOI to the publisher's website.

- The final author version and the galley proof are versions of the publication after peer review.

- The final published version features the final layout of the paper including the volume, issue and page numbers.

Link to publication

\section{General rights}

Copyright and moral rights for the publications made accessible in the public portal are retained by the authors and/or other copyright owners and it is a condition of accessing publications that users recognise and abide by the legal requirements associated with these rights.

- Users may download and print one copy of any publication from the public portal for the purpose of private study or research.

- You may not further distribute the material or use it for any profit-making activity or commercial gain

- You may freely distribute the URL identifying the publication in the public portal.

If the publication is distributed under the terms of Article 25fa of the Dutch Copyright Act, indicated by the "Taverne" license above, please follow below link for the End User Agreement:

https://www.ou.nl/taverne-agreement

Take down policy

If you believe that this document breaches copyright please contact us at:

pure-support@ou.nl

providing details and we will investigate your claim.

Downloaded from https://research.ou.nl/ on date: 26 Apr. 2023 
1Running head: PROCESS-ORIENTED WORKED EXAMPLES

This is a pre-print of: Van Gog, T., Paas, F., \& Van Merriënboer, J. J. G. (2006). Effects of processoriented worked examples on troubleshooting transfer performance. Learning and Instruction, 16, 154-164.

Copyright Elsevier, available online at http://www.elsevier.com/wps/find/journaldescription.cws home/956/description\#description

Effects of Process-Oriented Worked Examples on Troubleshooting Transfer Performance Tamara van Gog, Fred Paas, and Jeroen J. G. van Merriënboer Educational Technology Expertise Centre, Open University of the Netherlands, Heerlen, The Netherlands

Author Note:

Correspondence concerning this article should be addressed to Tamara van Gog, Open University of the Netherlands, Educational Technology Expertise Centre, P.O. Box 2960, 6401 DL, Heerlen, The Netherlands. E-mail: tamara.vangog@ou.nl.

This research project is funded by the Netherlands Organization for Scientific Research (NWO, The Hague, project no. 411-01-010).

The authors would like to extend a word of thanks to Nico Pluijmaekers (Arcus College, Heerlen), Roger Sliepen (Leeuwenborgh Opleidingen Sittard) and Louise Verhoeven (Leeuwenborgh Opleidingen Maastricht) for their practical help in conducting this study, to Mihály Koltai of DesignSoft, Inc. for making the TINA Pro software available free of charge for this study, and to the OTEC pub.group members for their comments on a previous draft of this article. 


\begin{abstract}
In the domain of electrical circuits troubleshooting, a full factorial experiment investigated the hypotheses that a) studying worked examples would lead to better transfer performance than solving conventional problems, with less investment of time and mental effort during training and test, and b) adding process information to worked examples would increase investment of effort during training and enhance transfer performance; whereas adding it to conventional problems would increase investment of effort, but would not positively affect transfer performance. The first hypothesis was largely confirmed by the data; the second was not: adding process information indeed resulted in increased investment of effort during training, but not in higher transfer performance in combination with worked examples.
\end{abstract}




\section{Effects of Process-Oriented Worked Examples on Troubleshooting Transfer Performance}

Troubleshooting, that is, diagnosing and repairing faults in a technical system, constitutes an important part of most technical jobs. Fault diagnosis is considered a complex cognitive skill to carry out, and even more complex to acquire (Gott, Parker Hall, Pokorny, Dibble, \& Glaser, 1993; Schaafstal, Schraagen, \& Van Berlo, 2000). This study addresses the question of how initial acquisition of this skill can be fostered by the design of effective troubleshooting instruction and, in particular, the support given to students during practice. Specially, the study investigates the effects on learning outcomes of support formats that are assumed to help students to use their cognitive resources more effectively.

According to Cognitive Load Theory (CLT; Sweller, 1988; Sweller, Van Merriënboer, \& Paas, 1998; Van Merriënboer \& Sweller, 2005) instructional materials draw on students' cognitive resources in three ways, related to the intrinsic, extraneous and germane cognitive load they impose. Intrinsic cognitive load is imposed by the complexity of the instructional task and depends on the number of interacting elements that have to be related, controlled, and kept active in working memory during learning activities. By nature, troubleshooting tasks are complex and require processing of numerous information elements. For example, in troubleshooting a simple electrical DC circuit, specific knowledge of the function of its components (e.g., voltage sources, resistors) and general knowledge about the relation between voltage, current and resistance (Ohm's law) and about the conservation of energy and charge (Kirchoff's laws) is needed to be able to determine how the circuit should function. Knowledge about how to use different meters is required to be able to measure the voltage, current and resistance at different points in the circuit. The troubleshooter has to compare those measurements to his/her own calculations of optimal functioning. Furthermore, s/he needs to relate the outcome of that comparison to knowledge about how certain symptoms (e.g., no current in the entire circuit) relate to certain 
faults (e.g., defect voltage source or open wire). And this is only an example of a very simple system; these circuits very often form just one subsystem in a more complex whole.

Ineffective, or extraneous cognitive load is imposed by the design of the instructional task or by the activities required of the learner and has been known to hamper learning. Effective cognitive load is also imposed by instructional design, but is germane to learning, as it focuses attention to activities relevant to the acquisition of knowledge and/or skills. Thus, in order to be effective, especially for tasks that impose a high intrinsic cognitive load such as troubleshooting, instruction should be designed in such a way that extraneous cognitive load is minimised and learners are challenged to use the resulting freed-up cognitive capacity for processes and activities directed at learning.

As the above example shows, troubleshooting tasks impose a high intrinsic cognitive load because effective performance requires the interactive use of system knowledge or given system information, principled domain knowledge, strategic knowledge and information provided through measurements conducted on the system, to reason about the system's (mal)functioning (Gitomer, 1988; Gott et al., 1993; Schaafstal, Schraagen, \& Van Berlo, 2000). Troubleshooting remains complex, even for highly experienced individuals. However, experience does offer tremendous advantages. For example, expert troubleshooters have well-developed cognitive schemas that contain quantitatively (more) and qualitatively (better) different system, principled, and strategic knowledge than novices' schemas do (Chi, Glaser, \& Rees, 1982; Larkin, McDermott, Simon, \& Simon, 1980). When troubleshooting familiar systems, experts can also use the case-based knowledge they gained through previous fault-finding experiences. When faced with unfamiliar systems troubleshooting, their schema-based knowledge assists them in more rapidly building a mental representation of that system than less experienced troubleshooters can (Egan \& Schwartz, 1979). These sophisticated mental representations can 
then be used to reason about the system's (mal)functioning.

Since novices lack both experience (case-based knowledge) and effective schemas, they have to keep in working memory all the system elements to construct an appropriate mental representation. Given that working memory capacity is limited to about 7 plus or minus 2 elements when merely holding information, and considerably less when processing it (Miller, 1956; Sweller, 2004), processing the system elements alone imposes very high demands on a novice's cognitive system. In fact, little capacity is likely to be left for reasoning based on this representation. Furthermore, when reasoning about system (mal)functioning, experts can rely on their strategic knowledge, which allows them to apply more effective strategies (e.g., the structured approach to troubleshooting described by Schaafstal et al., 2000), whereas novices have to rely on weaker strategies (using domain-general heuristics), which impose a high extraneous cognitive load (Sweller, 1988; Sweller et al., 1998).

Instruction that consists mainly of solving conventional problems (with only a formulation of criteria for an acceptable goal state and some "givens") forces novices to resort to weak problem-solving strategies (such as means-ends analysis), which is known to be ineffective for learning. By offering instructional formats that prevent the use of weak strategies, such as studying well-structured worked examples (possibly alternated with solving problems), extraneous cognitive load is reduced and learning is enhanced (Carroll, 1994; Cooper \& Sweller, 1987; Ward \& Sweller, 1990). Worked examples present the learner not only with the begin (or problem) state and a description of the criteria for an acceptable goal state as conventional problems do, but also show the solution steps that are to be taken to reach the goal state. So, the use of means-ends analysis is prevented because the learner does not have to search for a solution and can instead devote all available cognitive capacity to studying the given solution and constructing an appropriate problem schema (see Sweller, 1988). The 'worked example 
effect' demonstrates that for novices, instruction that relies more heavily on studying worked examples rather than exclusively conventional problem solving is superior with regard to learning outcomes, as measured by both near and far transfer tasks (for an overview of the benefits of worked examples, see Atkinson, Derry, Renkl, \& Wortham, 2000; Sweller et al, 1998; Sweller, 2004).

The cognitive capacity that is freed-up by reducing the extraneous load can -within working memory limits- be used to induce germane cognitive load activities that stimulate learning. For example, asking students to self-explain the solution steps may be an effective way to increase germane cognitive load and enhance learning (Chi, Bassok, Lewis, Reimann, \& Glaser, 1989; Renkl, 1997). The reason why worked examples require self-explaining is that the solution steps are given but the rationale for taking each step is not. Such examples can be called product-oriented (Van Gog, Paas, \& Van Merriënboer, 2004), because they show the problem solved, that is, which solution steps are applied to attain the goal state (the product). They do, however, not explain the problem-solving process, that is, why those steps are chosen (i.e., strategic knowledge) or why they are appropriate (i.e., principled knowledge). Recently, Van Gog et al. (2004) have argued that including in worked examples not only the solution steps, but also the strategic ("how") and principled ("why") information used in selecting the steps, may enhance learners' understanding of the solution procedure. This enhanced understanding due to given process information (i.e., "how" plus "why" information) is expected to lead to higher transfer test performance. Especially, far transfer performance can be expected to increase, because in contrast to near transfer tasks, which have structural features comparable to those of the training tasks but different surface features, far transfer tasks have different structural features, and therefore do not allow learners to merely apply a memorized procedure. Flexibly using those parts of a learned procedure that are relevant for a new (far transfer) problem 
requires that the learner understands the rationale behind (subgroups of) solution steps (cf. Catrambone, 1996, 1998), that is, "not only knows the procedural steps for problem-solving tasks, but also understands when to deploy them and why they work" (Gott et al., 1993, p. 260).

Research on either unsolicited or on-demand provision of only principle-based instructional explanations/elaborations in examples versus prompting for self-explanations, has suggested that prompting self-explanations is more effective for increasing transfer performance (e.g., Schworm \& Renkl, 2002). However, a precondition is that students are capable of providing high quality self-explanations, which is not always the case (see Chi et al., 1989; Lovett, 1992; Renkl, 1997). If this precondition is not met, providing high quality instructional explanations may improve performance (Lovett, 1992).

This study intended to empirically address the issues raised by Van Gog et al. (2004), by investigating the effectiveness for novices of a computer-simulated electrical circuits troubleshooting training program consisting of solving conventional problems with or without process information, and studying worked examples with or without process information (i.e., process-oriented and product-oriented worked examples). In line with consistent findings in the field of instructional design and CLT-inspired research (see Atkinson et al., 2000; Sweller, 2004), we hypothesized that practice consisting of studying worked examples would result in more effective learning than practice consisting of solving conventional problems. This 'worked example effect' would be demonstrated by higher near and — especially— far transfer test performance, with less investment of time and mental effort during both the training and the subsequent test.

Furthermore, we hypothesized that process information added to worked examples and conventional problems would result in higher investment of mental effort during practice compared to the conditions without process information (i.e., conventional problems and 
product-oriented worked examples). This higher investment of effort during practice is expected to produce differential effects on learning for the worked examples and conventional problems conditions (cf. Van Merriënboer, Schuurman, De Croock, \& Paas, 2002). Combined with worked examples, process information is expected to produce higher (far) transfer test performance than studying worked examples without process information would, because this higher effort is assumed to be an indication of germane load. Learners would be able to handle this germane load because extraneous load has been reduced through the implementation of worked-out solutions. Combined with conventional problems, in contrast, process information is expected to produce equally low or even lower transfer test performance than solving conventional problems without process information would, because the conventional problems already impose a high extraneous load. This would make it impossible to handle the process information in such a way that it facilitates learning.

Method

\section{Participants}

Sixty-eight first year electrotechnics students of three schools of senior secondary vocational education were asked to participate in the experiment. Because some of them did not attend school when the experiment took place, only 61 students actually participated (all male; age $M=17.04$ years, $S D=.90$ ). They were rewarded with $€ 7.50$. In the 4.5 months prior to the experiment, the school curricula (all schools used the same textbooks) offered electrotechnics instruction from which participants had gained the basic knowledge required to perform the experimental tasks. For example, students were given instruction in the function of basic circuit components such as voltage sources, resistors, ammeters, and voltmeters. They were familiarized with Ohm's law and Kirchoff's laws, and knew how to restate those laws in order to find an unknown value from the givens. They were also instructed on how to design basic parallel and 
series circuits. However, they had not yet acquired any troubleshooting experience.

Design

A $2 \times 2$ between-subjects factorial design, with the factors 'solution worked-out' (no/yes) and 'process information given' (no/yes) was used. The resulting four training conditions were: conventional problem solving (CP: no solution given, no process information), conventional problem solving with process information given (PCP: no solution given, process information), studying product-oriented worked examples (WE: solution given, no process information), and studying process-oriented worked examples (PWE: solution given, process information).

\section{Materials}

Training and test tasks. All experimental tasks were designed and delivered with TINA Pro software, version 6.0 (TINA = Toolkit for Interactive Network Analysis; DesignSoft, Inc., 2002) and consisted of malfunctioning electrical DC circuits simulations with one or two faults. The training tasks were preceded by an introduction to the TINA program (on paper) and an "introduction practice task" (in TINA) on which students could try out the functioning of the program described in the introduction. For example, participants could ascertain where to find the meter in the menu, how to use that meter, and how to repair a circuit component with TINA.

The training consisted of six parallel circuit tasks that contained the following faults: a resistor could be open, shorted, or its resistance could have changed to a higher or lower value than it should have according to the circuit diagram. In the first three tasks, those faults occurred in isolation and in the last three tasks two different faults occurred in combination, so that each fault occurred three times during the training: once in isolation and twice in combination with another fault. In the $\mathrm{CP}$ training condition, only the circuit diagrams were presented with a formulation of the criterion for an acceptable goal state (see Appendix A). In the PCP condition, the circuit diagrams, a formulation of the goal state criterion, and the process information (the 
text printed in bold and bold italics in Appendix B) was given. In the WE condition, the circuit diagram was shown, together with a formulation of the goal state criterion and a worked-out solution (the non-bold text in Appendix B). In the PWE condition, the circuit diagram, the goal state criterion formulation, and a worked-out solution complemented with the process information (Appendix B) was given.

The transfer test consisted, in order, of three near and three far transfer tasks. The structural features of the near transfer tasks were comparable to those of the training tasks: they were parallel circuit tasks with the same types of faults. The first near transfer task contained one fault, the second and third contained two different faults. The far transfer tasks had different structural features and consisted of one parallel circuit task with a new fault (voltage source) and two combined circuit (i.e., series-parallel) tasks with a familiar fault. The process information would be expected to lead to better performance on those tasks because it for example taught students to always measure again after repairing a component (higher likelihood of finding both faults in the near transfer tasks), and contained principles that helped identify the type of fault, and the faulty component's location in the circuit (for example knowing the principle that infinitely low current in the entire circuit -as opposed to in just one branch- involves an open component/wire outside the branches would result in a higher likelihood of finding the new fault).

Performance. On pre-printed training and test answer sheets, participants were asked to indicate for each task which components were faulty and to indicate what the fault was: the component: a) "is open", b) "is shorted", c) "has changed value: from ... (given in diagram) to ... ”, or d) "I do not know". They were instructed to fill out the values when they indicated 'c'. Although for both worked examples conditions the faulty components and the nature of the faults were given, participants in those conditions were asked to fill out the training answer sheet 
anyway, to ensure that this activity would not lead to time-on-task differences between conditions (i.e., to make sure that possible differences between the worked examples and conventional problems conditions are not due to the longer study time participants in the worked examples groups might have when they would not have to fill in the answer sheets).

Mental effort. On the answer sheets participants also had to indicate how much mental effort they invested to complete each task, on a 9-point rating scale ranging from 1 "very, very low effort" to 9 "very, very high effort" (Paas, 1992; Paas, Tuovinen, Tabbers, \& Van Gerven, 2003).

Time-on-Task. To be able to determine the time participants spent on each task, the screen coordinates of their mouse clicks and the time (in seconds) at which these were made, were logged with GazeTracker ${ }^{\mathrm{TM}}$ software (Lankford, 2000).

\section{Procedure}

Before the experiment, the 68 participants were randomly assigned to one of the four conditions, in such a way that each condition contained 17 participants. As mentioned in the 'participants' section, only 61 students actually participated, with 16 participants in the CP and PWE conditions, 15 in the PCP condition, and 14 in the WE condition. The study was run in five sessions in a computer room at the participants' respective schools. When participants arrived in the computer room, a PC was marked with their name, and the introduction and answer sheets were placed next to the PC. GazeTracker ${ }^{\mathrm{TM}}$ was already recording at that moment and the introduction practice task was already visible on the screen. Participants were instructed to start reading the introduction to the program and to familiarize themselves with the functioning of the program through the "introduction practice task". At this point, they were not yet allowed to start on the actual training tasks. When all participants had finished the introduction and had no more queries regarding the program, they were allowed to move on to the training tasks. Participants 
were allocated a maximum time of three minutes per training task, and although they could complete a task faster, they could not move on to the next task until three minutes had passed. On the test tasks, they were allowed to work at their own pace. Both during the training and the test, a "task list" was always visible on the right-hand side of their screen. When they had finished a task, they were instructed to click on the "submit" button, located under the "task list", before proceeding to the next task in that list. Participants could use a calculator ('real' or software) both during the training and the test, to ensure that simple computational errors would not affect task performance. After completing each task participants indicated the faulty component(s) and the type of fault(s), as well as the mental effort they invested in the task on the answer sheets.

After the experiment, participants' performance on the near and far transfer test tasks was scored in the following way. For each correctly diagnosed faulty component 1 point was given and for correct diagnosis of the fault in that component an additional point was given (and in case 'c' was indicated, but the value was wrong, $1 / 2$ point was given). So, the maximum mean performance score on the near transfer test tasks was 10 points $/ 3$ tasks $=31 \frac{1}{3}$ points (one task containing one fault with a maximum score of 2 points and two tasks containing two faults with a maximum score of 4 points each), and on the far transfer tasks it was 6 points $/ 3$ tasks $=2$ points (three tasks containing one fault with a maximum score of 2 points each).

Training and test time-on-task were calculated by first determining the screen coordinates of the tasks in the "task list" and of the "submit" button. Based on those coordinates, the time at which each task was selected and submitted could be determined from the mouse-click logging files. By subtracting the time of selection from the time of submission, the time-on-task was obtained. Due to recording errors, all time-on-task data were lost for three participants in the CP condition and two participants in the WE condition, test-time on task data were lost for on 
participant in the PWE condition, and training time-on-task data for one participant in PCP condition.

Results

Because of random assignment to conditions, it is unlikely that there are differences in prior knowledge between the conditions. An ANOVA on the performance scores on school exams of the subject matter (remember that all schools used the same textbooks) that were taken after 3 months of instruction (i.e., 1.5 months before the experiment) from participants of two schools ( $\mathrm{N}=48$; the third school could not provide this information), indeed showed no differences in exam performance between the four conditions $F(3,44)=.198, n s$. Hence, the results reported here are not likely to be artefacts of prior knowledge differences between conditions.

Data under analysis with respect to the training phase are mean training time-on-task (in seconds) and mean mental effort during the training. With regard to the test phase, the data under analysis are mean performance on near and far transfer test tasks, mean time spent on near and far transfer test tasks, and mean mental effort on near and far transfer test tasks. A series of 2 x 2 ANOVAs with 'solution worked out' and 'process information given' as between-subjects factors were conducted. The means and standard deviations for all dependent variables are presented in Table 1. Given the relatively large number of dependent variables examined, only the significant main and interaction effects are reported here. Cohen's $\mathrm{f}$ is provided as a measure of effect size, with $f=.10$ corresponding to a small effect, $f=.25$ to a medium, and $f=.40$ to a large effect (Cohen, 1988).

\section{Training Data}

The ANOVA on mean training time-on-task showed significant main effects for 'solution worked out,' $F(1,51)=9.18, M S E=517.64, p<.01, f=.39$, and for 'process information 
given, ${ }^{\prime} F(1,51)=6.60, M S E=517.64, p<.05, f=.32$, and a significant interaction effect, $F(1$, $51)=5.78, M S E=517.64, p<.05, f=.30$. The conditions with worked-out solutions (WE and PWE) showed lower time-on task $(M=146.04, S D=30.39)$ than the conditions without workedout solutions ( $\mathrm{CP}$ and PCP; $M=162.57, S D=17.45)$, and the conditions with process information (PCP and PWE) showed higher time-on-task $(M=160.99, S D=18.39)$ than the conditions without process information (CP and WE; $M=145.95, S D=31.44)$. The interaction (depicted in Figure 1) suggests that the availability of a worked-out solution had a large beneficial effect on time-on-task only when no process information was given, that is, the product-oriented worked-out examples group (WE) had to invest less time on the training tasks.

On mean mental effort during the training significant main effects in the expected direction were found for 'solution worked out', $F(1,57)=5.12, M S E=3.21, p<.05, f=.29$, and for 'process information given', $F(1,57)=4.05, M S E=3.21, p<.05, f=.26$. Specifically, participants in the conditions with worked-out solutions (WE and PWE) had to invest less mental effort during training $(M=4.59, S D=1.93)$ than their counterparts in the conditions without worked-out solutions (CP and PCP; $M=5.59, S D=1.72$ ). Furthermore, participants in the conditions with process information given (PCP and PWE) had to invest more mental effort during training $(M=5.53, S D=1.91)$ than participants in the conditions without this information (CP and WE; $M=4.66, S D=1.77)$.

\section{Test Data}

For the near transfer test, ANOVA on mean test performance yielded a significant main effect for 'solution worked out,' $F(1,57)=6.53, M S E=.44, p<.05, f=.34$. In line with our expectation, participants in the conditions with worked-out solutions (WE and PWE) obtained higher performance $(M=2.11, S D=.70)$ than participants in the conditions without worked-out solutions ( $\mathrm{CP}$ and PCP; $M=1.68, S D=.61)$. With respect to mean time-on-task, a significant 
main effect was also found for 'solution worked out,' $F(1,51)=14.68, M S E=5378.36, p<$. $001, f=.52$. This effect was, however, not in the expected direction: Participants who studied worked-out solutions (WE and PWE) spent more time on those test tasks $(M=232.04, S D=$ 90.09) than participants who had solved conventional problems (CP and PCP; $M=155.30, S D=$ 54.77). The fact that participants in the conditions with worked-out solutions spent more time on the test tasks might be a possible explanation for their higher performance. Therefore, an additional ANCOVA was performed with time-on-task as a covariate (for this analysis, the 6 participants' missing test time-on-task data were replaced with the means of their conditions). Again, a significant main effect on near transfer test performance, in the same direction, was found for 'solution worked out,' $F(1,56)=5.85, M S E=.44, p<.05, f=.33$. Thus, the extra time participants in the conditions with worked-out solutions spent on the near transfer test tasks did not explain their higher performance. Finally, for the mean mental effort invested in the near transfer test tasks, a significant main effect for 'process information given' was found, $F(1,57)$ $=10.00, M S E=2.64, p<.01, f=.41$. Participants in the conditions with process information (PCP and PWE) invested more mental effort in solving the test tasks $(M=6.00, S D=1.61)$ than participants in the conditions without this process information (CP and WE; $M=4.68, S D=$ $1.60)$.

The results on the far transfer test are in line with those on the near transfer test. The ANOVA on far transfer test performance yielded a significant main effect for 'solution worked out, $F(1,57)=5.99, M S E=.13, p<.05, f=.32$. As expected, participants in the conditions with worked-out solutions (WE and PWE) obtained higher performance $(M=1.30, S D=.40)$ than participants in the conditions without worked-out solutions (CP and PCP; $M=1.08, S D=$. 33). With respect to mean time-on-task on the far transfer test, no significant main or interaction effects were found. For the mean mental effort invested in this test, the pattern is the same as for 
the near transfer test with a significant main effect for 'process information given,' $F(1,57)=$ 5.02, $M S E=2.64, p<.05, f=.30$. Participants who received process information $(\mathrm{PCP}$ and PWE) invested more mental effort in solving the far transfer test tasks $(M=5.96, S D=1.50)$ than participants who did not receive such information (CP and WE; $M=5.02, S D=1.71$ ).

\section{Discussion}

The hypothesis that a training consisting of studying worked examples would lead to higher near and far transfer test performance, with less investment of time and mental effort during the training and the test, than a training consisting of solving conventional problems, was largely confirmed. Both on near and far transfer test tasks participants who had studied worked examples obtained a higher performance, with lower investment of effort and time on task during the training (the 'worked example effect'). Furthermore, the interaction between worked-out solution and process information showed a disproportionately low time-on-task for the productoriented worked examples group compared to the other groups, including the process-oriented worked examples group. With regard to investment of time and mental effort during the test, only a main effect on near transfer test time-on-task was found, and in the direction opposite of our prediction. Specifically, participants who had studied worked examples during training spent more time on the near transfer test tasks than participants who had solved conventional problems. The fact that they spent more time on those tasks could not, however, explain their higher transfer performance.

A possible explanation for this unexpected finding that studying worked examples did not result in decreased time-on-task and invested mental effort on the test tasks, might be that the duration of the training was to short for schema automation to occur. Schema construction was fostered, as is reflected in the higher performance outcomes. However, only when automation has been established can schemas be handled fast and effortlessly in working memory (Sweller, 
et al., 1998). The fact that near transfer test time-on-task was even higher for participants who had studied worked examples might be due to motivational aspects. Participants who had solved conventional problems during training may have given up on the test tasks when they felt that they would not be able to solve the problems. This would result in a (artificially) lower solution time.

The results clearly confirm the first part of the second hypothesis, process information added to worked examples and conventional problems resulted in higher investment of mental effort during the training compared to the conditions without process information. Participants who were given process information invested higher mental effort during practice tasks, near transfer test tasks, and far transfer test tasks. During practice, process information also increased time-on-task, which might be due to the additional processing of the "why" and "how" information. We did not, however, find any interaction effects of 'solution worked out' and 'process information given' on near and far transfer test performance. So, the second part of that hypothesis, that this higher investment of effort on the training would lead the process-oriented worked examples condition to obtain higher transfer test performance than the product-oriented worked examples condition, whereas it would lead the conventional condition with process information to obtain equal or even lower transfer performance than the conventional condition without that information, was not supported by our data.

There may be two possible explanations for why we did not find beneficial effects on performance of process information added to worked examples. The first is in terms of extraneous load. The 'split-attention effect' demonstrates that mutually referring information sources (e.g., text and diagram) that cannot be understood in isolation are best presented in an integrated format. For instance, by dividing the text into small pieces that can be included at the appropriate places in the diagram or by presenting the text as spoken sentences and 
simultaneously highlighting the parts of the diagram each sentence refers to. Thanks to the integrated format the learner is not required to switch attention between different information sources; a process that imposes an extraneous cognitive load that is not effective for learning (Chandler \& Sweller, 1992; Tarmizi \& Sweller, 1998; Ward \& Sweller, 1990). Whereas in our training tasks, the two types of text (worked-out solution and process information) in the process-oriented worked examples were integrated, they were not integrated in the diagram or presented as spoken text. Although text and diagram were separated for all worked examples, the text of the process-oriented worked examples was much longer than that of the product-oriented worked examples (see Appendix B for the information given with both types of worked examples). So, because of the short text, switching attention may not have imposed (high) extraneous load for participants studying the product-oriented worked examples, but may have imposed high extraneous load for those studying process-oriented worked examples. In sum, this first explanation refers to the fact that the form in which the process information was offered may have caused a high extraneous load, which resulted in more investment of effort during the training but not in higher performance. To test this explanation, future research should also use process-oriented worked examples in which texts are fully integrated with the diagram or in which the texts and diagrams are presented in an audiovisual format.

The second explanation is in terms of intrinsic cognitive load. Although intrinsic cognitive load is considered fixed because it is innate to the task (number of interacting elements), and instructional procedures are considered to influence only extrinsic (i.e., extraneous and germane) cognitive load (Ayres, in press; Sweller et al., 1998) adding process information in essence means adding extra information to the task. Although we conceived of this as an instructional procedure and expected it to induce a germane cognitive load, the fact that information was added to the task may have "changed" the task and increased the intrinsic 
cognitive load, (i.e., task complexity; see Ayres, in press); especially the principled information (Appendix B, bold italics text) is highly interactive with other information elements. Novice learners might not have been able to handle this increased complexity, even though the extraneous load was reduced through a worked-out solution (and this might even be the case when an integrated worked-out solution is presented). Therefore, it might have been better for novice learners if we had presented all or part of the process information before or after the worked example. This would be in accordance with the findings of Kester, Kirschner, and Van Merriënboer (in press), that presenting different types of information together, either before or during task execution, leads to lower learning efficiency than presenting one of these information types before and the other during task execution. More advanced learners have already acquired a basic problem schema and the task therefore imposes a lower intrinsic cognitive load for them. For that reason, they do not necessarily benefit from studying product-oriented worked examples (the 'expertise reversal effect'; Kalyuga, Ayres, Chandler, \& Sweller, 2003), but they might be able to use process-oriented worked examples to their advantage.

In sum, this second explanation refers to the fact that the content of the process information may have caused a too high intrinsic load for our participants, which resulted in more investment of effort during the training and the test, but not in higher performance. Future research should compare the effects of process-oriented worked examples for novice and advanced learners. Furthermore, it might be necessary to reconsider the definitions of the different kinds of cognitive load. Our instructional procedure differed from other procedures to induce germane cognitive load in the sense that self-explaining examples (Renk1, 1997), or being offered a sequence of examples with high variability (Paas \& Van Merriënboer, 1994), require different activities from learners than merely studying examples, but do not involve processing of additional information elements. Even though the process information may not change the 
task complexity in the sense that the ultimate target skills (effective performance of the task after the study phase) are not changed, it does make the "task" of studying the example more complex (by adding information elements that are interacting with other information elements).

Unfortunately, we have no means to support either of those theoretical explanations, since a pilot study with 4 first-year electrotechnical vocational education students had shown that they had great cognitive and motivational difficulties with thinking aloud (and those were students who volunteered), resulting in protocols of extremely poor quality. Hence, we decided not to implement a think aloud procedure in the experiment, as we had originally intended, but such kind of data would have been very informative.

The results of this study show that implementing more support in the form of worked examples in troubleshooting instruction will make that instruction more effective (lead to better transfer performance) as well as efficient (better performance is obtained with less investment of time and effort) for novice learners. This study also resulted in specific questions for further research that need to be addressed in order to find out whether and how additional support in the form of process information added to worked examples can be effective for novice learners. 


\section{References}

Atkinson, R. K., Derry, S. J., Renk1, A., \& Wortham, D. (2000). Learning from examples: Instructional principles from the worked examples research. Review of Educational Research, 70, 181-214.

Ayres, P. (in press). Using subjective measures to detect variations of intrinsic load within problems. Learning and Instruction.

Carroll, W. M. (1994). Using worked examples as an instructional support in the algebra classroom. Journal of Educational Psychology, 86, 360-367.

Catrambone, R. (1996). Generalizing solution procedures learned from examples. Journal of Experimental Psychology: Learning, Memory and Cognition, 22, 1020-1031.

Catrambone, R. (1998). The subgoal learning model: Creating better examples so that students can solve novel problems. Journal of Experimental Psychology: General, 12, 355-376.

Chandler, P., \& Sweller, J. (1992). The split-attention effect as a factor in the design of instruction. British Journal of Educational Psychology, 62, 233-246.

Chi, M. T. H., Bassok, M., Lewis, M. W., Reimann, P., \& Glaser, R. (1989). Self-explanations: How students study and use examples in learning to solve problems. Cognitive Science, $13,145-182$.

Chi, M. T. H., Glaser, R., \& Rees, E. (1982). Expertise in problem solving. In R. J. Sternberg (Ed.), Advances in the psychology of human intelligence (Vol. 1, pp. 7-76). Hillsdale, NJ: Erlbaum.

Cohen, J. (1988). Statistical power analysis for the behavioral sciences $\left(2^{\text {nd }}\right.$ ed.). Hillsdale, NJ: Erlbaum.

Cooper, G., \& Sweller, J. (1987). The effects of schema acquisition and rule automation on mathematical problem-solving transfer. Journal of Educational Psychology, 79, 347-362. 
DesignSoft, Inc. (2002). TINA Pro (Version 6) [Computer software]. Available from http://www.tina.com

Egan, D. E., \& Schwartz, B. J. (1979). Chunking in recall of symbolic drawings. Memory and Cognition, 7, 149-158.

Gitomer, D. H. (1988). Individual differences in technical troubleshooting. Human Performance, 1, 111-131.

Gott, S. P., Parker Hall, E., Pokorny, R.A., Dibble, E., \& Glaser, R. (1993). A naturalistic study of transfer: Adaptive expertise in technical domains. In D. K. Detterman and R. J. Sternberg (Eds.), Transfer on trial: Intelligence, cognition, and instruction (pp. 258-288). Norwood, NJ: Ablex.

Kalyuga, S., Ayres, P., Chandler, P., \& Sweller, J. (2003). The expertise reversal effect. Educational Psychologist, 38, 23-32.

Kester, L., Kirschner, P. A., \& Van Merriënboer, J. J. G. (in press). Just-in-time information presentation: Improving learning a troubleshooting skill. Contemporary Educational Psychology.

Lankford, C. (2000). GazeTracker ${ }^{\mathrm{TM}}$ : Software designed to facilitate eye movement analysis. Proceedings of the Eye Tracking Research and Applications Symposium (pp.57-63). New York: ACM Press.

Larkin, J., McDermott, J., Simon, D. P., \& Simon, H. A. (1980). Expert and novice performance in solving physics problems. Science, 208, 1335-1342.

Lovett, M. C. (1992). Learning by problem solving versus by examples: The benefits of generating and receiving information. In Proceedings of the $14^{\text {th }}$ Annual Conference of the Cognitive Science Society (pp. 956-961). Hillsdale, NJ: Erlbaum

Miller, G. A. (1956). The magical number seven, plus or minus two: Some limits on our capacity 
to process information. Psychological Review, 63, 81-97.

Paas, F. (1992). Training strategies for attaining transfer of problem-solving skill in statistics: A cognitive load approach. Journal of Educational Psychology, 84, 429-434.

Paas, F., Tuovinen, J. E., Tabbers, H., \& Van Gerven, P. W. M. (2003). Cognitive load measurement as a means to advance cognitive load theory. Educational Psychologist, 38, $63-71$.

Paas, F., \& Van Merriënboer, J. J. G. (1994). Variability of worked examples and transfer of geometrical problem-solving skills: A cognitive load approach. Journal of Educational Psychology, 86, 122-133.

Renkl, A. (1997). Learning from worked-out examples: a study on individual differences. Cognitive Science, 21, 1-29.

Schaafstal, A., Schraagen, J. M., \& Van Berlo, M. (2000). Cognitive task analysis and innovation of training: The case of structured troubleshooting. Human Factors, 42, 75-86.

Schworm, S., \& Renkl, A. (2002). Learning by solved example problems: Instructional explanations reduce self-explanation activity. In W. D. Gray \& C. D. Schunn (Eds.), Proceedings of the $24^{\text {th }}$ Annual Conference of the Cognitive Science Society (pp. 816821). Mahwah, NJ: Erlbaum.

Sweller, J. (1988). Cognitive load during problem solving: Effects on learning. Cognitive Science, 12, 257-285.

Sweller, J. (2004). Instructional design consequences of an analogy between evolution by natural selection and human cognitive architecture. Instructional Science, 32, 9-31.

Sweller, J., Van Merriënboer, J. J. G., \& Paas, F. (1998). Cognitive architecture and instructional design. Educational Psychology Review, 10, 251-295.

Tarmizi, R., \& Sweller, J. (1988). Guidance during mathematical problem solving. Journal of 
Educational Psychology, 80, 424-436.

Van Gog, T., Paas, F., \& Van Merriënboer, J. J. G. (2004). Process-oriented worked examples: Improving transfer performance through enhanced understanding. Instructional Science, $32,83-98$.

Van Merriënboer, J. J. G., Schuurman, J. G., de Croock, M. B. M., \& Paas, F. (2002). Redirecting learners' attention during training: Effects on cognitive load, transfer test performance, and training efficiency. Learning and Instruction, 12, 11-37.

Van Merriënboer, J. J. G., \& Sweller, J. (2005). Cognitive load theory and complex learning: Recent developments and future directions. Educational Psychology Review, 17, 147177.

Ward, M., \& Sweller, J. (1990). Structuring effective worked examples. Cognition and Instruction, 7, 1-39. 


\section{Appendix A}

\section{A Training Task (Conventional Problem)}

Note: $\mathrm{SW}=$ Switch, $\mathrm{VS}=$ Voltage Source, $\mathrm{R}=$ Resistor, $\mathrm{AM}=$ Ampère measurement point. The value of the voltage source and resistors is given after the component label $(\mathrm{V}=\mathrm{Volt}, \mathrm{k}=$ kilo $[\mathrm{Ohm}])$.

This circuit is not functioning correctly.

Find the fault(s) and repair the circuit so that it does function correctly.




Appendix B

Process-Information (Strategic in Bold and Principled in Bold and Italics) and the Worked-out

Solution (Normal Print) of the Problem shown in Appendix A

1. Determine how this circuit should function, using Ohm's law

(so what the current is that you should measure at the different measurement points)

In parallel circuits, the total current equals the sum of the currents in the parallel branches.

The total current should be It $=I 1+I 2+I 3$, or It $=U 1 / R 1+U 2 / R 2+U 3 / R 3$,

or It $=12 \mathrm{~V} / 6 \mathrm{kOhm}+12 \mathrm{~V} / 6 \mathrm{kOhm}+12 \mathrm{~V} / 3 \mathrm{kOhm}=2 \mathrm{~mA}+2 \mathrm{~mA}+4 \mathrm{~mA}=8 \mathrm{~mA}$.

You should measure:

$\mathrm{AM} 1=2 \mathrm{~mA}$

$\mathrm{AM} 2=2 \mathrm{~mA}$

$\mathrm{AM} 3=4 \mathrm{~mA}$

$\mathrm{AM} 4=8 \mathrm{~mA}$

2. Measure how it actually functions, using the Multimeter

(so what the current is that you actually measure at the different measurement points)

Go to T\&M > Multimeter and measure the current at AM1, AM2, AM3, and AM4. You get:

$\mathrm{AM} 1=2 \mathrm{~mA}$

$\mathrm{AM} 2=2 \mathrm{~mA}$

$\mathrm{AM} 3=12 \mathrm{nA}$

$\mathrm{AM} 4=4 \mathrm{~mA}$

3. Compare the outcomes of 1 and 2

They do not correspond, something is wrong.

4. Determine which component is faulty and what the fault in that component is, using the principles given below.

If the total current is lower than you would expect, the resistance in one or more of the parallel branches is too high (the same voltage [U] divided by a higher resistance [R] results in a lower current [I]).

If the total current is higher than you would expect, the resistance in one or more of the parallel branches is too low (the same voltage [U] divided by a lower resistance [R] results in a higher current [I]).

Infinitely low current in a parallel branch means that there is infinitely high resistance in that branch; very likely the resistor is open, but it can also be another component or the wire that is open.

No or infinitely low current in the entire circuit (in all branches) indicates that there is infinitely high resistance somewhere outside the branches; possibly the voltage source, the switch, or the wire outside the branches is open.

Infinitely high current in a parallel branch plus infinitely high total current indicates that the resistance is infinitely low; very likely the resistor in that one branch is shorted.

I3 = 12nA. Conclusion: R3 = open.

5. Repair the component

Repair R3.

6. Measure again

Go to $T \& M$ > Multimeter and measure the current at AM1, AM2, AM3, and AM4. You get: AM1 = $2 \mathrm{~mA}$

$\mathrm{AM} 2=2 \mathrm{~mA}$

$\mathrm{AM} 3=4 \mathrm{~mA}$

$\mathrm{AM} 4=8 \mathrm{~mA}$

7. Determine if the measures correspond to those you determined at step 1. If so, the circuit now functions correctly. If not, start over again at step 4.

The circuit now functions correctly. 
Table 1

Means and Standard Deviations of Time-on-Task and Mental Effort during Training and Test, and Test Performance as a Function of Experimental Condition

Experimental Condition

\begin{tabular}{|c|c|c|c|c|c|c|c|c|}
\hline \multirow[b]{3}{*}{ Dependent Variables } & \multicolumn{4}{|c|}{ Solution worked out } & \multicolumn{4}{|c|}{ Solution not worked out } \\
\hline & \multicolumn{2}{|c|}{ Process } & \multicolumn{2}{|c|}{ No process } & \multicolumn{2}{|c|}{ Process } & \multicolumn{2}{|c|}{ No process } \\
\hline & $M$ & $S D$ & $M$ & $S D$ & $M$ & $S D$ & $M$ & $S D$ \\
\hline \multicolumn{9}{|l|}{ Training } \\
\hline Time-on-task (s) & 159.19 & 17.18 & 128.51 & 35.76 & 163.06 & 20.13 & 162.04 & 14.83 \\
\hline Mental effort (1-9) & 5.10 & 1.93 & 4.01 & 1.82 & 5.98 & 1.85 & 5.22 & 1.56 \\
\hline \multicolumn{9}{|l|}{ Test-near transfer } \\
\hline Performance $(0-31 / 3)$ & 1.98 & .66 & 2.25 & .74 & 1.68 & .54 & 1.70 & .68 \\
\hline Time-on-task (s) & 247.60 & 99.00 & 212.58 & 77.24 & 172.49 & 44.70 & 135.46 & 60.19 \\
\hline Mental effort (1-9) & 6.27 & 1.43 & 4.62 & 1.57 & 5.71 & 1.80 & 4.73 & 1.68 \\
\hline \multicolumn{9}{|l|}{ Test -far transfer } \\
\hline Performance (0-2) & 1.21 & .44 & 1.40 & .35 & 1.13 & .37 & 1.02 & .28 \\
\hline Time-on-task (s) & 133.07 & 64.10 & 151.64 & 71.95 & 134.09 & 49.58 & 125.56 & 74.28 \\
\hline Mental effort (1-9) & 5.90 & 1.62 & 4.81 & 1.66 & 6.02 & 1.40 & 5.21 & 1.78 \\
\hline
\end{tabular}


Process-Oriented Worked Examples 28

\section{Figure Caption}

Figure 1. Interaction between the factors 'solution worked out' and 'process information given' on training time-on-task. 
- - - Not Worked-out Solution _ W Worked-out Solution

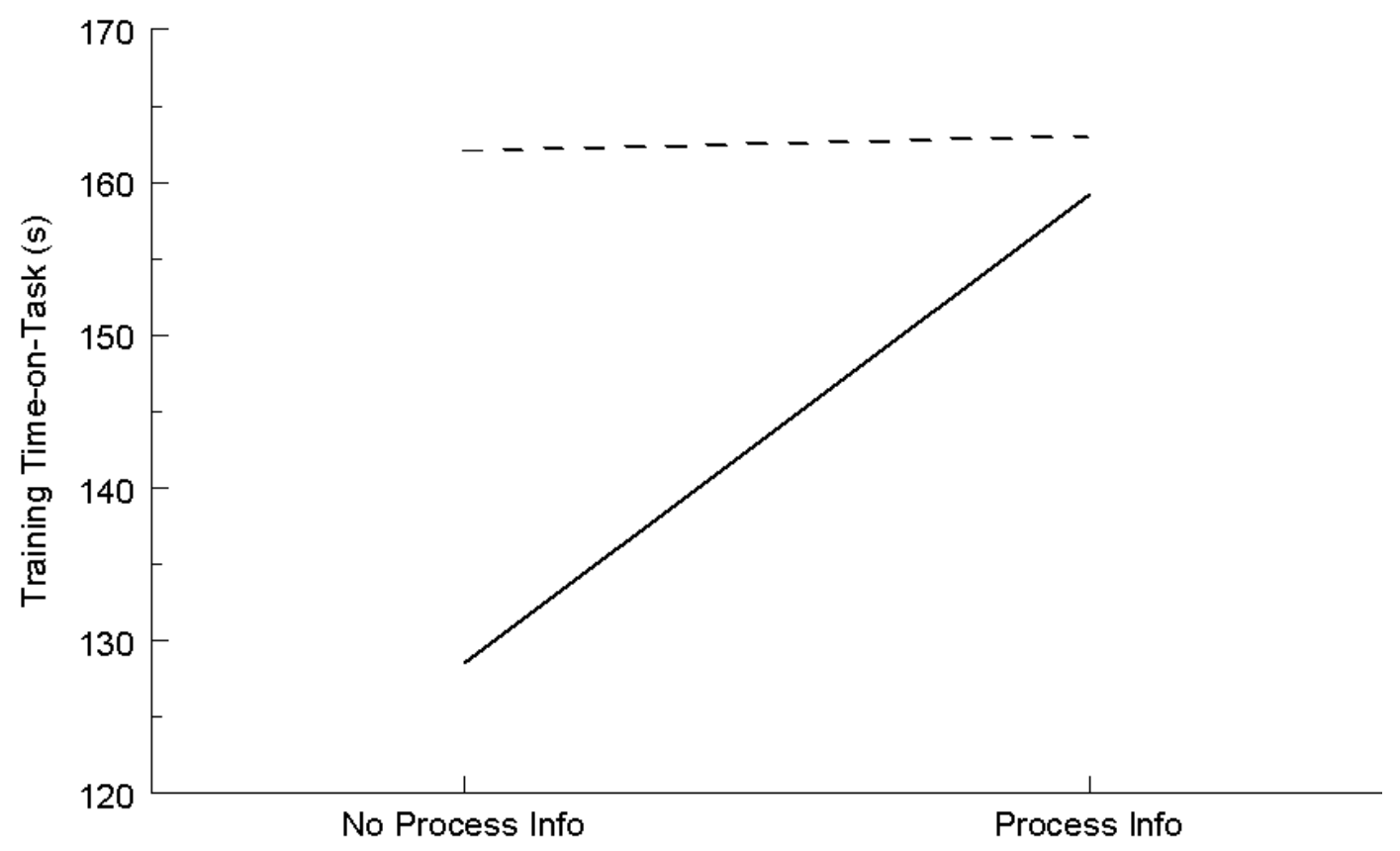

